\title{
A influência do preço de transferência na apuração do lucro real
}

\author{
Mario Alex Pedersen ${ }^{1}$ \\ Guilherme Pieri Pacheco ${ }^{2}$
}

\begin{abstract}
Resumo
Para evitar a remessa disfarçada de lucros entre companhias interligadas, a qual pode ocorrer por meio de uma compra superfaturada ou de uma venda subfaturada, foi estabelecida a legislação do preço de transferência, visando minimizar os impactos gerados sobre essas operações, por meio de cálculos pré-estabelecidos. Assim sendo, o objetivo desse trabalho foi evidenciar a influência do Preço de Transferência na apuração do Imposto de Renda (IRPJ) e da Contribuição Social sobre o Lucro (CSLL) para uma sociedade industrial tributada pelo Lucro Real Anual. O estudo tem natureza de pesquisa aplicada e, quanto aos objetivos, classificou-se como pesquisa descritiva e exploratória. Quanto aos procedimentos técnicos, trata-se de uma pesquisa documental e um estudo de caso. A abordagem do problema se dá por meio da pesquisa qualitativa. Os dados foram coletados no setor de contabilidade e referem-se ao ano de 2015. Pode-se inferir que, com a revisão dos cálculos do preço de transferência, apurou-se um provável passivo de aproximadamente R \$ 18,7 milhões.
\end{abstract}

Palavras-chave: Preço de Transferência; Lucro real; Imposto de renda.

\section{The influence of the transfer pricing on the calculation of the annual taxable income}

\begin{abstract}
In order to avoid covert remittance of profits between interconnected companies, which may occurs through an overpriced purchase or an underpricing sale, it was established regulations regarding the transfer pricing which seeks to minimize impacts generated on these operations, through pre-established calculations. Therefore, the aim of this study was to demonstrate the influence of the Transfer Pricing in the calculation of Income Tax (IRPJ) and Social Contribution on Net Income (CSLL) for an industrial corporation taxed on Annual Taxable Income. The research typifies as applied nature and regarding objectives are ranked in descriptive and exploratory research. As for the technical procedures it is a documentary research and a case study. The approach to the problem relates to qualitative research. Data were collected in the accounting sector and covered the calendar year of 2015. This research reveals, though the review of the calculation of the transfer pricing, a probable liability of approximately $\mathrm{R} \$ 18.7$ million.
\end{abstract}

Keywords: Transfer Pricing; Taxable Income; Income Tax.

\section{INTRODUÇÃO}

\footnotetext{
${ }^{1}$ Contador. Docente no IFRS Campus Porto Alegre. mario.pedersen@poa.ifrs.edu.br

${ }^{2}$ Contador. guilherme.pieri.pacheco@gmail.com
} 
No cenário globalizado atual, a maioria das grandes companhias possui filial ou empresas vinculadas espalhadas por todas as partes do mundo, tornando-se, dessa forma, cada vez mais competitivas dentro do seu ramo de atuação. Destarte, faz-se necessário que estas grandes corporações mantenham o controle de todas as suas operações.

Diante da possibilidade de remessa de lucro nas operações entre empresas vinculadas no exterior - por meio do superfaturamento das importações e do subfaturamento das exportações, ou até mesmo nas operações com sociedades estabelecidas em paraísos fiscais, com intuito de redução da elevada carga tributária sobre os rendimentos - as relações internacionais entre empresas de um mesmo grupo tornam-se de grande importância para o cálculo dos Preços de Transferência.

Nesse contexto, com base nos artigos 18 a 24 da Lei $n^{\circ} 9.430 / 96$, estabeleceu-se legalmente no Brasil o regime de preços de transferência, internacionalmente conhecido como "Transfer Price". O cálculo dos preços de transferência surgiu com o intuito de evitar a prática lesiva aos cofres públicos pela manipulação de preços nas operações de importações e exportações de bens ou direitos e serviços.

A partir da promulgação da Lei $n^{\circ}$ 9.430/96, a Receita Federal do Brasil (RFB) passou a regulamentares determinados métodos de cálculo para a apuração dos preços praticados, a fim de reestabelecer a tributação sobre valores que até então eram livremente remetidos para o exterior.

A companhia Omega, Sociedade Anônima de capital fechado, que serviu de objeto para as análises contidas neste trabalho, controla quatro empresas situadas na América do Sul e uma companhia na Ásia. Todo o grupo é voltado para a produção e comercialização de artigos de vestuário e produtos esportivos. No Brasil, a empresa possui diversas unidades e o faturamento no ano de 2015 foi de aproximadamente R\$ 600 milhões.

Nesse cenário, a companhia Omega efetuou diversas operações de aquisição e venda com as suas empresas controladas no ano de 2015. Ficou assim, sujeita à aplicação do cálculo do preço de transferência, de modo a demonstrar que as operações atenderam aos preceitos legais estabelecidos pelas regras brasileiras, ou, na impossibilidade, realizar os ajustes necessários na apuração do Imposto de Renda (IRPJ) e da Contribuição Social sobre o Lucro Líquido (CSLL), sanando qualquer eventual sanção sobre o tema.

Com base no apresentado, elaborou-se o seguinte problema de pesquisa: Qual a influência do Preço de Transferência na apuração do IRPJ e da CSLL para a Omega que é tributada pelo Lucro Real Anual? 
O objetivo geral do presente estudo consiste em: Evidenciar a influência do Preço de Transferência na apuração do Imposto de Renda (IRPJ) e da Contribuição Social sobre o Lucro (CSLL) para a Omega que é tributada pelo Lucro Real Anual.

Como meio para atingir o objetivo geral da pesquisa, elaboraram-se os seguintes objetivos específicos:

(1) Demonstrar o cálculo dos Preços de Transferência praticados nas operações de exportação;

(2) Explicar os cálculos por meio dos Métodos permitidos pela legislação;

(3) Comparar os resultados tributários gerados por meio da aplicação dos métodos possíveis para a Companhia Omega.

Devido à elevada carga tributária para as empresas no cenário nacional, às constantes alterações na legislação tributária e à inclusão de diversas obrigações acessórias a serem seguidas pelos contribuintes, no que tange ao Imposto de Renda da Pessoa Jurídica e a Contribuição Social Sobre o Lucro Líquido, esse trabalho justifica-se pela perspectiva de utilização do cálculo do preço de transferência como ferramenta de gestão para as empresas, procurando contornar a percepção de punição inerente à obrigação de efetuar o cálculo.

Buscando descomplexar os métodos de cálculos e fundamentar as alterações nos preços a serem praticados, entre empresas participantes de um mesmo grupo empresarial, por meio da realização periódica do cálculo, é possível mitigar eventuais prejuízos. Tais danos podem ocorrer devido ao desconhecimento de que as operações de compra e venda, que até então vinham sendo realizadas com percentuais satisfatórios para a empresa, encontram-se em desconformidade com as margens estabelecidas pela normatização da Receita Federal do Brasil.

\section{Referencial teórico}

Neste trabalho, aborda-se a Contabilidade Tributária como ferramenta de gestão para as empresas, a importância dos tributos e contribuições que, conforme fonte do IBGE e da Receita Federal Brasileira, chegou a corresponder a uma carga de aproximadamente 33,47\% do PIB nacional, no ano de 2014. Voltado para o Imposto de Renda da Pessoa Jurídica e a Contribuição Social Sobre o Lucro Líquido, no que tange ao impacto do cálculo do Preço de Transferência para esse imposto e essa contribuição. 


\subsection{Contabilidade tributária}

A Contabilidade Tributária é uma das áreas de estudo das Ciências Contábeis que tem por objetivo gerenciar os tributos incidentes sobre as atividades das empresas. A importância dessa área se justifica pelas obrigações tributárias exigidas pelos órgãos reguladores da União, Estados e Municípios, haja vista que a Contabilidade Tributária é usada como instrumento de gestão, com o intuito de produzir informações de forma adequada acerca da arrecadação e fiscalização de tributos.

Para Oliveira (2009, p. 5), a contabilidade tributária "tem como função utilizar as regras e princípios para interpretar e aplicar com base na legislação a apuração dos proventos a serem tributados".

Segundo Iudícibus et al., (2010, p. 1), a Contabilidade Tributária "é uma ciência social, que foi concebida para captar, registrar, acumular, resumir e interpretar situações que impactam o patrimônio", fornecendo informações econômicas e sociais a todos os interessados. Já para Fabretti (2009), o objeto da Contabilidade Tributária é apurar com exatidão o resultado econômico social, atendendo as exigências das legislações pertinentes ao Imposto de Renda da Pessoa Jurídica (IRPJ) e à Contribuição Social sobre o Lucro (CSLL), determinando a base de cálculo fiscal ou tributária, para em seguida formar o valor de provisão desses tributos.

Com base nos conceitos supracitados, conclui-se que a Contabilidade Tributária é um ramo da contabilidade que tem por finalidade gerir os tributos apurados sobre os fatos geradores de uma empresa. Além disso, essa área busca minimizar os impactos financeiros gerados com as apurações dos tributos e não expor a entidade às possíveis sanções fiscais previstas na legislação brasileira.

\subsection{Tributos}

Conforme definido no art. $3^{\circ}$ do Código Tributário Nacional (Brasil, 1966) (CTN), "tributo é toda prestação pecuniária compulsória, em moeda ou cujo valor nela se possa exprimir, que não constitua sanção de ato ilícito, instituída em lei e cobrada mediante atividade administrativa plenamente vinculada", podendo ser divididos tributos em diretos e indiretos. Diretamente impactados pelos efeitos do preço de transferência, tem-se os Impostos e as Contribuições. 
Os impostos destinam-se a cobrir necessidades públicas gerais. Segundo Fabretti (2009, p. 105), o imposto não está vinculado a nenhuma atuação estatal específica relativa ao contribuinte. Já a contribuição, segundo Machado (2010, p. 437), tem sua finalidade constitucionalmente definida e pode ser dividida em contribuição de intervenção no domínio econômico, interesse de categorias profissionais ou econômicas e seguridade social.

\subsection{Imposto de renda e contribuição social}

Segundo o artigo 220 do Decreto 3.000 (Brasil, 1999) (Regulamento do Imposto de Renda - doravante denominado "RIR"), a base de cálculo do IRPJ e CSLL podem ser determinadas pelas seguintes formas de apuração: lucro real, lucro presumido, lucro arbitrado e pelo simples nacional. Será abordada a explicação sobre o Lucro Real, modalidade que a companhia analisada está obrigada a apurar o Imposto de renda.

\subsubsection{Lucro real}

O Lucro Real é um conceito fiscal definido, conforme art. 247 do RIR, como o lucro líquido do período de apuração ajustado pelas adições, exclusões ou compensações prescritas ou autorizadas. Tais ajustes são escriturados no Livro de Apuração do Lucro Real (LALUR), livro criado pelo Decreto-Lei $n^{\circ}$. 1.598 (Brasil, 1977) para a realização de cálculos extracontábil, para apurar a base para o Imposto de renda e da Contribuição Social.

Tem-se por lucro líquido, conforme Decreto 3.000 (Brasil, 1999), o registro de todos os fatos patrimoniais, todas as receitas, custos e despesas. Assim, o fato gerador do imposto de renda ocorre a partir da disponibilidade econômica ou jurídica, assim entendida como renda e proventos de qualquer natureza.

Segundo Fabretti (2009, p. 204), “o fato gerador desenvolve-se durante todo o ano calendário, ou seja, inicia-se em janeiro e seu encerramento dá-se em dezembro", portanto, o resultado econômico é conhecido apenas no fim do exercício, através dos resultados mensais que podem ser positivos e negativos, observando o regime de competência.

Também importa ressaltar que a apuração pode ser realizada de forma Real Trimestral (quatro competências de apuração no ano) e Real Anual (o qual poderá ter estimativas mensais ou balanço de suspensão e redução) e ao final do ano-calendário de 12 (doze) meses consecutivos a sociedade deverá, a partir do ano calendário de 2014, apresentar uma Escrituração Contábil Fiscal (doravante denominada ECF). 
O IRPJ faz parte dos tributos diretos, aos quais a Constituição Federal encarrega competência à União (Brasil, 1988) para a cobrança de tal imposto. Seu montante é determinado pela aplicação da alíquota de $15 \%$ sobre a base de cálculo e o adicional de $10 \%$ sobre o que exceder a $\mathrm{R} \$ 240.000,00$ ao ano, ou $\mathrm{R} \$ 20.000,00$ por mês na base de cálculo.

Já a CSLL foi criada pela Lei no. 7.689 (Brasil, 1988), com o intuito de aumentar as contribuições ao Governo Federal e assim financiar a seguridade social. Bem como o IRPJ, tal contribuição tem como fato gerador a receita e proventos de qualquer natureza, tendo a cobrança de competência da União.

Na prática, a base de cálculo da Contribuição Social é similar a do Imposto de Renda, salvo algumas exceções. A alíquota a ser aplicável, conforme Lei n. 7.689 (Brasil, 1988), ao lucro tributável é de $9 \%$ para as pessoas jurídicas em geral e $15 \%$ para instituições financeiras, tendo sido essa última, majorada para $20 \%$ para o período de $1^{\circ}$ de setembro de 2015 a 31 de dezembro 2018.

O art. 14 da Lei nº 9.718 (Brasil, 1998), alterado pela Lei $n^{\circ} .10 .637$ (Brasil, 2002) e posteriormente alterado pela Lei $\mathrm{n}^{\mathrm{o}}$. 12.814 (Brasil, 2013), deixa claro quais são as pessoas jurídicas obrigadas à apuração do Imposto de Renda com base no lucro real.

Entram nessa classificação as pessoas jurídicas que auferiram receita no anocalendário anterior superior ao limite de $\mathrm{R} \$ 78$ milhões de reais; que pratiquem a atividade de bancos comerciais, de investimento e desenvolvimento, sociedades de crédito, financiamento, corretoras de títulos, empresas de arrendamento mercantil, cooperativas de créditos, empresas de seguro, capitalização e previdência privada, factoring. Ainda aquelas que obtiveram lucros, rendimentos ou ganhos de capital auferidos no exterior. Também estão obrigadas ao lucro real, as empresas que efetuarem o pagamento do imposto pelo regime de estimativa, as que gozem de benefícios fiscais relativos à isenção ou redução do imposto, dentre outras.

A empresa objeto deste estudo, por estar enquadrada nesse regime de tributação, era obrigada a entregar anualmente o LALUR até o ano calendário de 2013, a partir de 2014 e tal entrega ocorre junto a ECF conforme IN 1.422 (Brasil, 2013).

\subsection{Preço de transferência}

Em virtude do forte crescimento registrado nas operações entre as multinacionais, fruto da globalização, tornou-se de grande importância o controle dos Preços de Transferência que, na visão de Gregorio (2011, p. 39), "não visam necessariamente à economia de tributos, mas também podem ser motivadas pela presença de incentivos financeiros, restrições cambiais, pressões salariais, entre outros". Por outro lado, o preço de transferência deixa a 
possibilidade de se obter uma vantagem através da transferência de renda tributável entre as competências fiscais.

De acordo com Machado (2010, p. 32), essencialmente, os métodos são uma tentativa de estabelecer uma média de preços para que seja possível efetuar as comparações e regrar com transparência o que é caracterizado como uma evasão de divisas entre as "pessoas vinculadas".

Assim, o controle dos Preços de Transferência é indispensável, independente de gerar ou não ajuste na base de cálculo do IRPJ e CSLL.

\subsubsection{Preço de Transferência no Brasil}

Em sintonia com a tendência internacional, no Brasil, foi editada a Lei $\mathrm{n}^{\circ} 9.430$ (Brasil, 1996) que, pelos artigos 18 a 24, passaram a regular tal prática nacionalmente. A regulamentação surgiu com a intenção de defender os interesses nacionais diante da vulnerabilidade dos processos internos dentro das organizações em trocar informações entre empresas de um mesmo grupo econômico.

O objetivo do cálculo dos Preços de Transferência é a comparação entre o preço de um produto importado ou exportado de uma pessoa vinculada com o preço de maior valor nas importações e de menor valor nas exportações. Conforme Duarte (2005, p. 17), o cálculo dos Preços de Transferência "busca limitar a transferência indireta de lucros embutidos nos preços, nos negócios realizados entre entidades brasileiras com outras, vinculadas, domiciliadas no exterior".

Assim, de acordo com a Lei $n^{\circ} 9.430$ (Brasil, 1996), se a diferença entre o preço praticado e o preço parâmetro for inferior nas importações e superior nas exportações, a diferença deverá ser ajustada nas bases de cálculo do Imposto de Renda e da Contribuição Social, evitando distorções na tributação do IRPJ e CSLL da sociedade.

Conforme Lei $\mathrm{n}^{\circ} 9.430$ (Brasil, 1996), a finalidade do cálculo dos Preços de Transferência, na importação, é limitar a dedutibilidade das despesas e, na exportação, é reconhecer as receitas e rendimentos. Dessa forma, as operações abrangidas para fins de cálculo são: a compra e venda de bens e direitos, a contratação de serviços e a contratação de mútuo sem registro no Banco Central do Brasil.

Portanto, toda a entidade que for obrigada a realizar o cálculo dos Preços de Transferência fica obrigada, de acordo com o Manual de Orientação da ECF, a preencher as informações das operações realizadas na ECF (Escrituração Contábil Fiscal), evidenciando, assim, as suas atividades econômicas. 
Nos casos de operações com países de tributação favorecida, conhecidos como Paraísos Fiscais, o cálculo deverá ser realizado independente de a operação ser realizada com pessoas físicas ou jurídicas vinculadas, conforme IN nº 1.312 (Brasil, 2012).

\subsubsection{Pessoas Vinculadas}

As pessoas vinculadas são empresas que possuem relação direta ou indireta por meio de uma ou mais entidades, cujas transações referem-se a operações tais como: transferência de recursos, serviços, compra e venda, prestação ou recebimento de serviços, etc. $\mathrm{O}$ art. $2^{\circ}$ da IN $\mathrm{n}^{\circ} 1.312$ (Brasil, 2012) passou a definir pessoas vinculadas como a matriz, filial, sucursal, pessoa física ou jurídica domiciliada no exterior e também empresa que, em conjunto com a pessoa jurídica localizada no Brasil, tenha participação societária no capital social de uma terceira pessoa jurídica.

Nesse sentido, Higuchi (2005, p. 154) diz "que a vinculação mais comum ocorre entre matriz e filial, controladora e controlada".

A IN no 1.312 (Brasil, 2012), em seu $\S 5^{\circ}$ do art. 2, estabelece ainda a aplicabilidade das normas sobre o preço de transferência para as operações realizadas por meio de pessoa interposta, ou que ocorram de forma exclusiva seja para um tipo de bem, serviço ou direito, que ocorra somente entre duas pessoas jurídicas. Nota-se que controladas e coligadas são:

Controlada: Sociedade na qual a controladora é titular direta ou através de outras controladas, de direitos dos sócios, de modo que possam eleger os administradores e predominância nas deliberações sociais.

Coligadas: Sociedade na qual a investidora tenha influência significativa. A Lei ${ }^{\circ}$ 6.404/76 (Brasil, 1976) dispõe que a influência significativa ocorre quando a investidora detém ou exerce poder de eleger a maioria dos administradores, participar nas decisões políticas financeiras ou operacionais da investida, e também se for titular de no mínimo $20 \%$ (vinte por cento) do capital votante da investida, sem controlá-la.

\subsubsection{Paraísos Fiscais}

Na opinião de Vieira (2010, p. 261), “o conceito sobre paraíso fiscal pode variar, sendo que alguns entendem como um refúgio apenas para burlar a lei e outros como uma oportunidade para redução da carga tributária". O autor ainda afirma que as características de estabilidade política, ausência de controles burocráticos e sigilo bancário também contribuem 
para que empresas realizem seus planejamentos tributários utilizando-se dos países conhecidos como paraísos fiscais.

Desse modo, Paraísos Fiscais são países que não tributam a renda ou que tributam a alíquotas inferiores a $20 \%$, podendo ainda se caracterizarem por uma legislação interna que não permite acesso às informações econômicas e financeiras das pessoas jurídicas, conforme definido pela IN no 1.037 (Brasil, 2010). Ainda está contido nessa IN, os países classificados como Paraísos Fiscais, bem como formas de constituições de pessoas jurídicas com regimes fiscais privilegiados em alguns países.

\section{5 métodos de cálculo dos preços de transferência}

Neste item, identificam-se os métodos aceitos atualmente pela legislação brasileira para a efetivação dos cálculos dos Preços de Transferência nas operações de importações e exportações, realizadas entre pessoas vinculadas domiciliadas no exterior e paraísos fiscais.

Nota-se que, conforme IN no 1.312 (Brasil, 2012), a empresa poderá optar por qual dos métodos deseja realizar o cálculo dos Preços de Transferência de seus bens, serviços e direitos, desde que possua a documentação que comprove a determinação do preço de comparação escolhido. Entretanto, a escolha será válida para todo o ano-calendário vigente, não podendo ser alterada após iniciado procedimento de fiscalização, salvo nos casos em que a empresa não consiga comprovar a devida adequação do método em questão e este venha a ser desqualificado por fiscalização desempenhada pela Receita Federal do Brasil.

O método escolhido pela sociedade pode vir a ser desqualificado caso a pessoa jurídica deixe de apresentar documentos e memórias de cálculo que suportem as operações ou até mesmo que apresentem documentação insuficiente, podendo, neste caso, apresentar um novo cálculo no prazo de 30 dias. (IN nº 1.312, Brasil, 2012)

A seguir, definem-se os principais conceitos envolvidos nas operações de exportações e importações, de acordo com a IN nº 1.312 (Brasil, 2012):

- Custo de aquisição: valor pelo qual o bem ou serviço é adquirido;

- Preço praticado: média ponderada de preços pelos quais a sociedade efetivamente comprou ou vendeu um produto, deverá ser calculado produto por produto;

- Preço Parâmetro: média ponderada de preços praticados entre sociedades independentes e ajustados de acordo com os métodos definidos pela legislação brasileira, servirá de referência na comparação com o preço praticado, também deve ser calculado por produto; 
- Margem de divergência: variação do percentual de 5\% para mais ou para menos do preço praticado, ou 3\% em caso de commodities. É considerada satisfatória a comprovação, nas operações com empresas vinculadas, quando o preço ajustado, a ser utilizado como parâmetro, divirja, em até cinco por cento, para mais ou para menos, daquele constante dos documentos de importação ou exportação para a não realização do ajuste de preços de transferência;

- Similaridade: quando os bens apresentarem mesma natureza, tiverem especificações paralelas ou que possam substituir-se;

- Pessoa Interposta: quando uma pessoa intermedia operações entre pessoas vinculadas;

- Margem de Lucro: percentuais estipulados pela legislação brasileira sobre os preços de venda/aquisição.

O cálculo dos Preços de Transferência nas importações visa limitar a dedutibilidade de despesas na apuração da base de cálculo do IRPJ e CSLL. Desta forma, torna-se imprescindível o conhecimento efetivo dos custos, despesas e encargos incidentes sobre os bens, serviços ou direitos importados. (IN nº 1.312, Brasil 2012)

Somente a partir desses dados será possível que a sociedade escolha pela aplicação de um dos métodos sugeridos pela RFB para determinação do cálculo do preço de transferência. (IN nº 1.312, Brasil 2012)

Depois de identificados os principais conceitos comuns as importações e exportações, discorrem-se acerca dos métodos aceitos pela $\mathrm{IN} \mathrm{n}^{\circ} 1.312$ (Brasil, 2012):

\subsubsection{Método dos Preços Independentes Comparados - PIC}

A IN nº 1.312 (Brasil, 2012) dispõe que o PIC consiste:

“(...) na média aritmética ponderada dos preços de bens, serviços ou direitos, idênticos ou similares, apurados no mercado brasileiro ou de outros países, em operações de compra/venda entre compradores e vendedores não vinculados, em condições de pagamentos semelhantes. (...)"

Pode-se afirmar que o método utilizado é de comparação dos bens, serviços ou direitos idênticos ou similares.

A partir do ano calendário de 2013, conforme IN n ${ }^{\circ} 1.312$ (Brasil, 2012), a sociedade deve ter no mínimo 5\% do valor de suas importações sujeitas ao cálculo dos Preços de Transferência. 
Entretanto, não havendo a quantidade de operações necessárias, o percentual mínimo para o cálculo poderá ser complementado com importações realizadas no ano-calendário imediatamente anterior, observado o ajuste de variação cambial do período atual. (IN $\mathrm{n}^{\mathrm{o}}$ 1.312, Brasil 2012)

\subsubsection{Método do Preço de Revenda menos Lucro - PRL}

O Preço de Revenda menos Lucro consiste na média ponderada dos preços de venda realizados sobre as importações realizadas sujeitas ao cálculo, deduzidos dos descontos incondicionais, juros e impostos incidentes sobre a importação, as comissões e corretagens conforme a IN nº 1.312 (Brasil, 2012). Esta comparação serve para que o preço de revenda interno goze de uma margem mínima de $20 \%$ a mais que o valor do bem importado. (NEPOMUCENO 2003, p. 78)

As margens sobre o lucro, de acordo com a IN no 1.312 (Brasil, 2012), são aplicadas conforme com a atividade da empresa, sendo: I) 40\% (setores: produtos farmoquímicos e farmacêuticos, produtos de fumo, equipamentos e instrumentos ópticos, fotográficos e cinematográficos, máquinas, aparelhos e equipamentos para uso odontomédico-hospitalar, extração de petróleo e gás natural e produtos derivados do petróleo); II) 30\% (setores: produtos químicos, vidros e produtos de vidro, celulose, papel e produtos de papel e metalurgia) e III) $20 \%$ (para os demais setores).

Ainda no que diz respeito às margens de lucro previstas, cabe salientar que essas devem ser usadas independente do bem, serviço ou direito vir a ser aplicado à produção ou revendido e serão aplicadas sobre o preço de venda da nota fiscal, excluindo apenas os descontos incondicionais, conforme previsto na IN no 1.312 (Brasil, 2012).

\subsubsection{Método do Custo de Produção mais Lucro - CPL}

De acordo com a IN n 1.312 (Brasil, 2012), o método é calculado a partir do "custo médio ponderado da produção de bens, serviços ou direitos, idênticos ou similares, acrescidos os impostos e taxas cobrados no país de origem e de margem de lucro de $20 \%$ sobre o custo".

Este método serve para definir o preço do exportador (empresa vinculada), tomando por base o custo médio de produção do bem (NEPOMUCENO 2003, p. 94), ou seja, o preço da exportação não pode ultrapassar o custo de produção mais a margem de lucro de $20 \%$.

\subsubsection{Métodos aceitos nas exportações}


O cálculo dos Preços de Transferência nas exportações visa evitar a evasão de lucros do país, ou seja, garantir que a receita seja tributada dentro do país de origem, integrando, dessa forma, as bases de cálculo do IRPJ e CSLL.

Para fins de comparação, a IN nº 1.312 (Brasil, 2012), prevê que o preço de venda nas exportações deverá ser líquido de descontos incondicionais, de Imposto sobre Circulação de Mercadorias e Prestação de Serviço (ICMS), do Imposto sobre Serviços de Qualquer Natureza (ISS), Programa de Integração Social (PIS), Contribuição para o Financiamento da Seguridade Social (COFINS), fretes e seguros quando suportados pela empresa vendedora.

Ao que diz respeito às regras gerais das exportações, deve-se lembrar que as receitas recebidas de pessoas vinculadas estão sujeitas a arbitramento, caso o preço de venda de bens, serviços ou diretos seja inferior a $90 \%$ do preço de venda no mercado brasileiro. No caso da pessoa jurídica não realizar vendas internas, poderão ser utilizado dados de outras empresas que tenham vendas internas de bens, serviços ou direitos idênticos ou similares. (IN $\mathrm{n}^{\mathrm{o}} 1.312$ de Brasil, 2012, art. 20).

\subsubsection{Método do Preço de Venda nas Exportações - PVEx}

Conforme IN no 1.312 (Brasil, 2012), o PVEx consiste na média aritmética dos preços de venda nas exportações realizadas pela empresa, para terceiros, ou para exportadora de bens, serviços ou direitos, idênticos ou similares, durante o mesmo ano-calendário de apuração da base de cálculo do imposto de renda e contribuição social.

2.5.4.2 Método do Preço de Venda por Atacado no País de Destino, Diminuído do Lucro PVA

Embasa-se na média aritmética dos preços de venda de bens, idênticos ou similares, praticados no mercado atacadista do país de destino, diminuídos os tributos incluídos no preço e de margem de lucro de quinze por cento sobre o preço de venda, de acordo com a IN $n^{\circ}$ 1.312 (Brasil, 2012).

\subsubsection{Método do Preço de Venda a Varejo no País de Destino, Diminuído do Lucro - PVV}

Baseia-se na média aritmética dos preços de venda de bens, idênticos ou similares, praticados no mercado varejista do país de destino, diminuídos dos tributos incluídos no preço e de margem de lucro de trinta por cento sobre o preço de venda no varejo, segundo IN $n^{\circ}$ 1.312 (Brasil, 2012). 
A forma de cálculo do PVV é a mesma mencionada no item anterior do PVA, apenas deve-se lembrar que a margem de lucro neste método é de $30 \%$, e a comparação será realizada com os preços constantes no mercado varejista do país de destino.

\subsubsection{Método do Custo de Aquisição ou de Produção mais Tributos e Lucro - CAP}

Fundamenta-se na média aritmética dos custos de aquisição ou de produção dos bens, serviços ou direitos a serem exportados, acrescidos dos impostos e contribuições cobrados no Brasil e de margem de lucro de quinze por cento sobre a soma dos custos, incluindo os impostos e contribuições, em concordância com a IN no 1.312 (Brasil, 2012).

\section{Procedimentos metodológicos}

Pode-se conceituar método como a ordem que se deve impor aos diferentes processos necessários para se atingir o resultado desejado. É o conjunto de processos na demonstração da verdade (CERVO, et al., 2006, p. 27). A presente pesquisa é de natureza aplicada, porque o estudo contribuiu para o conhecimento da apuração do preço de transferência e utilização desse como ferramenta de gestão por parte da companhia Omega.

Em relação aos objetivos, classifica-se em pesquisa descritiva e exploratória. A pesquisa descritiva, segundo (CERVO, et al. 2006, p. 61), "consiste em observar, registrar, analisar e correlacionar fatos ou fenômenos sem manipulá-los". Desenvolve-se principalmente nas ciências sociais, e seu registro não consta em documentos, precisando, dessa forma, ser coletado. Já a pesquisa exploratória, segundo Cervo (2006), tem como objetivo familiarizar o problema de pesquisa, com vistas a torná-lo mais explícito.

Quanto aos procedimentos técnicos, o presente estudo classifica-se como pesquisa documental e estudo de caso. De acordo com Silva (2010, p. 55), a pesquisa documental "consiste em materiais que ainda não receberam tratamento analítico ou que podem ser reelaborados, classificada de fontes públicas (documentos oficiais) e fontes privadas (relatórios gerenciais, demonstrativos, tabelas estatísticas, entre outros)". No que diz respeito ao estudo de caso, Beuren (2008 apud GIL 1999, p. 73) diz que "é caracterizado pelo estudo de um ou poucos objetos, de maneira que se possam obter conhecimentos amplos e detalhados do mesmo".

Utilizaram-se como documentos para a realização do estudo as planilhas de cálculo da empresa Omega e documentos amostrais para comprovação dos dados contidos nas planilhas. 
No tocante à abordagem do problema, a pesquisa se define como qualitativa. Para Beuren et al (2008, p. 92), ressalta-se que a análise qualitativa não se pretende numerar ou medir unidades, diferentemente da análise quantitativa que caracteriza-se pelo emprego de instrumentos estatísticos, tanto na coleta de dados quanto no tratamento das informações obtidas.

Quanto à população e à amostra do presente estudo, recorreu-se a Beuren et al (2008), que classifica a população como a totalidade de elementos distintos que possui certa paridade nas características para determinado estudo. De uma forma macro, pode ser formada pela coleção de propriedades ou atributos das unidades que estão em estudo.

No entanto, quando se tem um grande número de elementos a serem estudados, fazse necessário a seleção de uma amostragem, ou seja, a escolha de apenas uma parte dos itens da população, de modo que se torne a mais representativa possível e se obtenham as informações necessárias a partir dos resultados alcançados (BEUREN, 2008).

Assim, a população é a Companhia Omega, sociedade atuante no segmento industrial de vestuário e calçados. A amostra compreendeu as informações dos relatórios gerencias, colhidos através do contador responsável pelo departamento contábil e fiscal da sociedade. A amostragem é classificada como não probabilística intencional e foi baseada nas informações do ano-calendário de janeiro a dezembro de 2015 , com base nos produtos que registraram os maiores ajustes de preços de transferência.

Segundo Lakatos e Marconi (2003, p. 165), “os instrumentos de coleta de dados é uma etapa da pesquisa em que se inicia a aplicação dos instrumentos elaborados e das técnicas selecionadas, a fim de se efetuar a coleta dos dados previstos". Para Cervo (2006, p. 83), "a coleta de dados é a fase da pesquisa em que se registram informações, interpretam-se os dados reunidos e da classificação deles".

Após a coleta de dados e a obtenção dos resultados, o próximo passo é a análise e interpretação dos mesmos. A análise é a tentativa de evidenciar as relações existentes entre o fenômeno e outros fatores, já a interpretação procura dar significado às respostas (LAKATOS e MARCONI, 2003, p. 167).

Em resumo, os dados apresentados nesta pesquisa foram analisados e apresentados a partir da técnica qualitativa de natureza aplicada, ou seja, por meio de tabelas de cálculo dos possíveis ajustes decorrentes do preço de transferência, dos itens selecionados, os quais serviram de base para a apresentação do resultado final da pesquisa. 


\section{Análise descritiva dos dados}

A companhia Omega, Sociedade Anônima de capital fechado, controla quatro empresas situadas na América do Sul e uma empresa na Ásia. Todo o grupo é voltado para a produção e comercialização de artigos de vestuário e produtos esportivos. No ano de 2015 , a companhia Omega efetuou diversas operações de aquisição e venda com as suas empresas controladas, ficando assim sujeita à aplicação do cálculo de preço de transferência.

Além dos documentos normalmente emitidos pela pessoa jurídica nas importações e exportações, Fabretti (2009, p. 273) leciona que os custos e preços médios para determinação do Preço de Transferência também podem ser apurados com base em relatórios oficiais, pesquisas realizadas por empresa especializadas, publicações técnicas, entre outros. Contudo, conforme o art. 43 da IN n ${ }^{\circ} 1.312$ (Brasil, 2012), tais documentos serão admitidos como prova se estiverem de acordo com os critérios internacionais de avaliação, sob pena de serem descartados pela Receita Federal do Brasil se considerados irregulares.

Com base no exposto, é de extrema importância as empresas manterem de forma clara e organizada a documentação necessária para comprovação dos cálculos, evitando, com isto, as possíveis sansões administrativas fiscais.

Por meio da documentação fornecida pela empresa, na qual constavam os cálculos, verificou-se que, sobre as operações de exportação realizadas com as empresas vinculadas, foi utilizado, para 116 produtos, o método de cálculo PVA.

Apresentam-se a seguir as tabelas resumos do cálculo com os 15 produtos que representaram os maiores impactos em relação aos riscos identificados no ano de 2015.

A tabela 1 contém as informações sobre os produtos, quantidades e preço de exportação.

Tabela 1: Exportação realizada sujeita ao cálculo do preço de transferência.

\begin{tabular}{|c|c|c|c|c|c|c|}
\hline \multicolumn{4}{|c|}{ 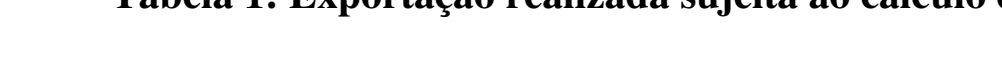 } & \multirow{2}{*}{\begin{tabular}{c|} 
(A) \\
$\begin{array}{c}\text { Exportado } \\
\text { líquido }\end{array}$
\end{tabular}} & \multirow{2}{*}{\begin{tabular}{|c|} 
(B) \\
Quantidade
\end{tabular}} & \multirow{2}{*}{$\begin{array}{c}\text { Exportado } \\
\text { unitário }\end{array}$} \\
\hline Grupo & Produto & Descrição & Unid. & & & \\
\hline Interligadas & 549378 & TENIS MASCULINO & PAR & $97.834,80$ & 2280 & 42,91 \\
\hline Interligadas & 619108 & TENIS WHITE/BLUE & PAR & $166.191,72$ & 2004 & 82,93 \\
\hline Interligadas & 603397 & TENIS MASCULINO & PAR & $128.444,40$ & 2520 & 50,97 \\
\hline Interligadas & 603400 & TENIS MASCULINO & PAR & $128.444,40$ & 2520 & 50,97 \\
\hline Interligadas & 597723 & TENIS - W - PRETO/AZUL/PINK & PAR & $102.873,60$ & 2280 & 45,12 \\
\hline Interligadas & 597784 & TENIS TURQ/LARANJA/LIMAO & PAR & $123.459,60$ & 2640 & 46,77 \\
\hline Interligadas & 549381 & TENIS FEMININO & PAR & $128.730,00$ & 3000 & 42,91 \\
\hline
\end{tabular}

ReFAE - Revista da Faculdade de Administração e Economia, v. 9, n. 1, p. 168-190, 2018 


\begin{tabular}{l|l|l|l|l|r|r}
\hline Interligadas & 604623 & TENIS FEMININO & PAR & $154.133,28$ & 3024 & 50,97 \\
\hline Interligadas & 600899 & TENIS FEMININO & PAR & $128.730,00$ & 3000 & 42,91 \\
\hline Interligadas & 604626 & TENIS FEMININO & PAR & $154.133,28$ & 3024 & 50,97 \\
\hline Interligadas & 597702 & TENIS - W - AZUL/PRETO/PINK & PAR & $122.172,48$ & 2832 & 43,14 \\
\hline Interligadas & 539588 & TENIS - GRAF/PRETO/ROXO & PAR & $163.083,60$ & 3312 & 49,24 \\
\hline Interligadas & 539582 & TENIS - GRAF/BRANCO/AZUL & PAR & $192.692,16$ & 3888 & 49,56 \\
\hline Interligadas & 597700 & TENIS - GRAFITE/AZUL/PINK & PAR & $155.304,00$ & 3600 & 43,14 \\
\hline Interligadas & 539469 & TENIS - W - PINK/BRANCO & PAR & $211.555,56$ & 5076 & 41,68 \\
\hline
\end{tabular}

Fonte: elaborada pelos autores

Nessa primeira tabela, é possível verificar os dados referentes às operações que originaram a obrigação de proceder ao cálculo, tendo em vista que são as informações de venda de exportação, efetuadas pela empresa situada no Brasil, para com sua empresa controlada no exterior.

Assim, demonstram-se os campos necessários para obter-se o preço praticado conforme os critérios para o cálculo do método PVA. Este servirá de base para comparação e determinação de eventuais impactos na apuração do Imposto de Renda (IRPJ) e da Contribuição Social (CSLL).

A tabela 2 contempla as informações referentes ao preço praticado no atacado do país que adquiriu as mercadorias do Brasil. Tais informações foram fornecidas pela empresa situada no exterior, a qual disponibilizou documentação comprobatória, evidenciando os valores de receita sobre esses produtos, os valores de descontos e impostos que podem ser descontados para fins de determinação do preço parâmetro.

Tabela 2: Dados de Venda no Atacado do País de Destino.

\begin{tabular}{c|c|c|c|c|c|c}
\hline $\mathbf{( C )}$ & $\mathbf{( D )}$ & $\mathbf{E})$ & & & $(\mathbf{G})$ & \\
\hline Venda Bruta & Desconto & Imposto & $\begin{array}{c}\text { Vendido margem } \\
15 \%\end{array}$ & $\begin{array}{c}\text { Vendido Líq. } \\
\text { Total }\end{array}$ & $\begin{array}{c}\text { Vendido } \\
\text { quantidade }\end{array}$ & $\begin{array}{c}\text { Vendido } \\
\text { unit. } \\
\text { (Parâmetro) }\end{array}$ \\
\hline $914.667,81$ & $136.591,27$ & $34.235,37$ & $116.711,48$ & $627.129,69$ & 2163 & 289,94 \\
\hline $1.220 .770,74$ & $124.255,46$ & $48.246,67$ & $164.477,29$ & $883.791,32$ & 2279 & 387,80 \\
\hline $1.091 .319,48$ & $87.463,40$ & $44.169,67$ & $150.578,41$ & $809.108,00$ & 2404 & 336,57 \\
\hline $1.081 .959,12$ & $92.739,19$ & $43.525,68$ & $148.382,99$ & $797.311,26$ & 2408 & 331,11 \\
\hline $1.008 .348,72$ & $105.876,59$ & $39.708,77$ & $135.370,82$ & $727.392,54$ & 2712 & 268,21 \\
\hline $1.088 .865,60$ & $102.766,89$ & $43.388,34$ & $147.914,81$ & $794.795,56$ & 2796 & 284,26 \\
\hline $1.217 .865,60$ & $170.653,30$ & $46.077,34$ & $157.081,85$ & $844.053,11$ & 2880 & 293,07 \\
\hline $1.316 .477,15$ & $124.810,12$ & $52.433,35$ & $178.750,05$ & $960.483,63$ & 2939 & 326,81 \\
\hline $1.263 .535,56$ & $153.704,79$ & $48.832,55$ & $166.474,62$ & $894.523,60$ & 2988 & 299,37 \\
\hline $1.356 .883,38$ & $129.456,99$ & $54.006,76$ & $184.113,96$ & $989.305,67$ & 3033 & 326,18 \\
\hline $1.166 .537,67$ & $112.365,85$ & $46.383,56$ & $158.125,77$ & $849.662,49$ & 3183 & 266,94 \\
\hline $1.168 .908,93$ & $105.468,88$ & $46.791,36$ & $159.516,01$ & $857.132,68$ & 3480 & 246,30 \\
\hline $1.354 .480,94$ & $113.244,00$ & $54.614,43$ & $186.185,54$ & $1.000 .436,97$ & 4054 & 246,78 \\
\hline
\end{tabular}

ReFAE - Revista da Faculdade de Administração e Economia, v. 9, n. 1, p. 168-190, 2018 


\begin{tabular}{l|l|l|l|l|l|l}
\hline $1.530 .480,24$ & $146.603,33$ & $60.890,58$ & $207.581,54$ & $1.115 .404,79$ & 4356 & 256,06 \\
\hline $2.121 .377,33$ & $191.075,48$ & $84.933,28$ & $289.545,28$ & $1.555 .823,29$ & 6737 & 230,94 \\
\hline
\end{tabular}

Fonte: elaborada pelos autores

Igualmente, conforme os critérios estabelecidos pela IN nº 1.312 (Brasil, 2012) para o cálculo do método PVA, para a apuração de eventuais ajustes na determinação do Imposto de Renda e da Contribuição Social.

Com as informações apresentadas nas Tabelas 1 e 2, é possível realizar o cálculo utilizando o método PVA. Evidencia-se a seguir o impacto gerado na Pessoa Jurídica Brasileira, na tabela a seguir.

Tabela 3: Quantificação dos Ajustes na Apuração do Lucro Real Cálculo PVA

\begin{tabular}{|c|c|c|c|c|c|}
\hline $\begin{array}{c}\text { Venda Líquida = } \\
(\text { C-D- E-(C*85\%)) } \\
=\mathbf{F}\end{array}$ & $\begin{array}{l}\text { Preço Praticado } \\
\quad=(\mathbf{F} / \mathbf{G})=\mathbf{I}\end{array}$ & $\begin{array}{l}\text { Preço Parâmetro = } \\
(\mathrm{A} / \mathrm{B})=\mathbf{H}\end{array}$ & $\begin{array}{l}\text { Diferença } \\
\text { Unitária = } \\
(\mathbf{I}-\mathbf{H})=\mathbf{J}\end{array}$ & $\%$ & $\begin{array}{l}\text { Ajuste Total } \\
\quad=(\mathbf{J} * \mathbf{B})\end{array}$ \\
\hline $627.129,69$ & 289,94 & 42,91 & 247,03 & $576 \%$ & $563.217,30$ \\
\hline $883.791,32$ & 387,80 & 82,93 & 304,87 & $368 \%$ & $610.955,19$ \\
\hline $809.108,00$ & 336,57 & 50,97 & 285,60 & $560 \%$ & $719.705,42$ \\
\hline $797.311,26$ & 331,11 & 50,97 & 280,14 & $550 \%$ & $705.951,11$ \\
\hline $727.392,54$ & 268,21 & 45,12 & 223,09 & $494 \%$ & $508.651,10$ \\
\hline $794.795,56$ & 284,26 & 46,77 & 237,50 & $508 \%$ & $626.991,14$ \\
\hline $844.053,11$ & 293,07 & 42,91 & 250,16 & $583 \%$ & $750.491,99$ \\
\hline $960.483,63$ & 326,81 & 50,97 & 275,84 & $541 \%$ & $834.128,88$ \\
\hline $894.523,60$ & 299,37 & 42,91 & 256,46 & $598 \%$ & $769.386,06$ \\
\hline $989.305,67$ & 326,18 & 50,97 & 275,21 & $540 \%$ & $832.236,77$ \\
\hline $849.662,49$ & 266,94 & 43,14 & 223,80 & $519 \%$ & $633.794,90$ \\
\hline $857.132,68$ & 246,30 & 49,24 & 197,06 & $400 \%$ & $652.670,26$ \\
\hline $1.000 .436,97$ & 246,78 & 49,56 & 197,22 & $398 \%$ & $766.779,71$ \\
\hline $1.115 .404,79$ & 256,06 & 43,14 & 212,92 & $494 \%$ & $766.518,14$ \\
\hline $1.555 .823,29$ & 230,94 & 41,68 & 189,26 & $454 \%$ & $960.681,20$ \\
\hline
\end{tabular}

Fonte: elaborada pelos autores

Para calcular o valor da Receita de Venda Líquida no Atacado do país que efetuou as importações do produto brasileiro, é permitido pela IN nº 1.312 (Brasil, 2012), realizar o desconto dos tributos incidentes na venda, bem como dos descontos incondicionais. Ademais, foi determinado como aceitável uma margem de lucro de $15 \%$ sobre o valor bruto da venda.

Sobre o valor resultante da equação, efetuou-se a divisão pela quantidade de produto comercializado, assim, obtendo o preço parâmetro.

Já para o preço praticado, também seria possível descontar os impostos e descontos concedidos, contudo, a operação de exportação já é incentivada com a desoneração de tributos, e não ocorreu concessão de descontos. Desse modo, utilizou-se o valor da receita de

ReFAE - Revista da Faculdade de Administração e Economia, v. 9, n. 1, p. 168-190, 2018 
venda de exportação da empresa situada no Brasil e dividiu-se pela quantidade de produto exportado, para obter-se o preço praticado na operação.

Comparando o preço parâmetro unitário com o preço praticado unitário, resultando em diferença positiva (preço parâmetro superior ao preço praticado) para uma operação de exportação, deve-se efetuar a multiplicação da diferença obtida pela quantidade de produto exportado, para determinar o ajuste total.

Somente não será necessário realizar ajuste nos casos em que a diferença obtida represente até $5 \%$ do valor unitário da operação de importação ou exportação, conforme previsto no Art. 51, da IN nº 1.312 (Brasil, 2012).

Como essa não é a situação que ocorreu nas análises, procede-se o ajuste sobre todas as operações que foram consideradas o método PVA. A tabela a seguir demonstra a quantificação da contingência passiva, considerando o cenário mais negativo que a companhia Omega poderia enfrentar com relação ao cálculo dos produtos apresentados nas tabelas anteriores.

Tabela 4: Quantificação Total

\begin{tabular}{c|rr}
\hline Total Base & R\$ & $\mathbf{3 1 . 0 8 3 . 4 2 2 , 1 4}$ \\
\hline IRPJ & R\$ & $\mathbf{7 . 7 7 0 . 8 5 5 , 5 3}$ \\
\hline CSLL & R\$ & $\mathbf{2 . 7 9 7 . 5 0 7 , 9 9}$ \\
\hline Risco Imposto $^{(1)}$ & R\$ & $\mathbf{1 0 . 5 6 8 . 3 6 3 , 5 3}$ \\
\hline Multa $^{(1)}$ & $\mathbf{R} \$$ & $\mathbf{7 . 9 2 6 . 2 7 2 , 6 4}$ \\
\hline Juros $^{(2)}$ & $\mathbf{R} \$$ & $\mathbf{2 2 8 . 2 7 6 , 6 5}$ \\
\hline Risco Total $^{2}$ & R\$ & $\mathbf{1 8 . 7 2 2 . 9 1 2 , 8 2}$ \\
\hline
\end{tabular}

(1) Multa de 75\% em caso de lançamento de ofício conforme Inciso I, Art. 44, Lei 9.430/1996

(2) Atualização Selic acumulada de fevereiro a março de 2016 no total de 2,16\%

Fonte: elaborada pelos autores

Para determinação da quantificação total do risco, foi considerado que a empresa não estava adicionando nenhum valor de ajuste na apuração do lucro real, em relação ao método de cálculo PVA. Na hipótese da companhia sofrer um procedimento de fiscalização por parte da Receita Federal, haveria um lançamento de ofício de 75\% de multa. O Imposto de Renda e a Contribuição Social relativos ao ano-calendário de 2015 têm como data de vencimento 31/01/2016. Logo, os juros foram atualizados para os meses de fevereiro e março de 2016, com base no índice da Selic.

Com base na representatividade do risco identificado, os diretores da Companhia Omega decidiram alterar o método de cálculo para o CAP sobre essas operações. O artigo 40 da IN nº 1.312 (Brasil, 2012) permite a alteração do método a ser aplicado durante todo o ano- 
calendário, desde que ainda não tenha sido iniciado qualquer processo de fiscalização, ou que a alteração não tenha sido solicitada pela autoridade fiscal, caso o cálculo esteja sendo realizado sem atender critérios estabelecidos.

A tabela 5 apresenta os dados relativos ao custo para que a companhia Omega produzisse os produtos. Considerando a contingência identificada pelo método PVA, procurou-se verificar se a realização do cálculo por outro método apresentaria um melhor cenário para a empresa.

Tabela 5: Dados relativos ao custo

\begin{tabular}{c|c|c}
\hline$(\mathbf{L})$ & $(\mathbf{M})$ & $(\mathbf{N})$ \\
\hline Custo total & Quantidade & Custo unitário \\
\hline $80.244,26$ & 2.280 & 35,19 \\
\hline $109.550,02$ & 2.004 & 54,67 \\
\hline $119.045,29$ & 2.520 & 47,24 \\
\hline $110.979,41$ & 2.520 & 44,04 \\
\hline $87.921,20$ & 2.280 & 38,56 \\
\hline $114.378,86$ & 2.640 & 43,33 \\
\hline $106.978,28$ & 3.000 & 35,66 \\
\hline $126.862,13$ & 3.024 & 41,95 \\
\hline $116.338,59$ & 3.000 & 38,78 \\
\hline $137.813,34$ & 3.024 & 45,57 \\
\hline $113.005,81$ & 2.832 & 39,90 \\
\hline $122.437,81$ & 3.312 & 36,97 \\
\hline $155.461,70$ & 3.888 & 39,99 \\
\hline $146.508,28$ & 3.600 & 40,70 \\
\hline $195.076,97$ & 5.076 & 38,43 \\
\hline
\end{tabular}

Fonte: elaborada pelos autores

Para estabelecer o preço parâmetro, em se tratando do método CAP, é necessário obter o custo total dos bens produzidos e dividir pela respectiva quantidade de bens gerados, obtendo-se assim o custo unitário. Sobre o valor de custo unitário, a Companhia Omega deverá aplicar uma margem mínima de lucro de $15 \%$, para o alcance do preço parâmetro. Um aspecto interessante em relação ao método CAP é que, para realização do cálculo, todas as informações já se encontram em poder da empresa brasileira (informações da venda e informações do custo).

A tabela a seguir apresenta os cálculos da quantificação do cálculo pelo método CAP.

Tabela 6: Quantificação dos Ajustes na Apuração do Lucro Real - Cálculo CAP 


\begin{tabular}{|c|c|c|c|c|c|}
\hline $\begin{array}{c}\text { Custo Unitário = } \\
(\mathbf{L} / \mathbf{M})=\mathbf{N}\end{array}$ & $\begin{array}{c}\text { Margem de } 15 \%=( \\
N * 115 \%)=0\end{array}$ & $\begin{array}{c}\text { Preço Praticado }=( \\
\text { A } / \mathbf{B})=\mathbf{H}\end{array}$ & $\begin{array}{l}\text { Diferença Unitária } \\
\quad=(\mathbf{O}-\mathbf{H})=\mathbf{P}\end{array}$ & $\%$ & $\begin{array}{l}\text { Ajuste Total } \\
=(\mathbf{P} * \mathbf{B})\end{array}$ \\
\hline 35,19 & 40,47 & 42,91 & - & $0 \%$ & - \\
\hline 54,67 & 62,87 & 82,93 & - & $0 \%$ & - \\
\hline 47,24 & 54,33 & 50,97 & 3,36 & $7 \%$ & $8.457,68$ \\
\hline 44,04 & 50,65 & 50,97 & - & $0 \%$ & - \\
\hline 38,56 & 44,35 & 45,12 & - & $0 \%$ & - \\
\hline 43,33 & 49,82 & 46,77 & 3,06 & $7 \%$ & $8.076,09$ \\
\hline 35,66 & 41,01 & 42,91 & - & $0 \%$ & - \\
\hline 41,95 & 48,24 & 50,97 & - & $0 \%$ & - \\
\hline 38,78 & 44,60 & 42,91 & 1,69 & $4 \%$ & - \\
\hline 45,57 & 52,41 & 50,97 & 1,44 & $3 \%$ & - \\
\hline 39,90 & 45,89 & 43,14 & 2,75 & $6 \%$ & $7.784,20$ \\
\hline 36,97 & 42,51 & 49,24 & - & $0 \%$ & - \\
\hline 39,99 & 45,98 & 49,56 & - & $0 \%$ & - \\
\hline 40,70 & 46,80 & 43,14 & 3,66 & $8 \%$ & $13.180,52$ \\
\hline 38,43 & 44,20 & 41,68 & 2,52 & $6 \%$ & $12.782,96$ \\
\hline
\end{tabular}

Fonte: elaborada pelos autores

Ressaltando que as informações foram mantidas na mesma ordem, e que a Tabela 1 corresponde a operação de exportação concretizada e que originou a obrigação da realização do cálculo do preço de transferência, foi mantida para ambos o cálculo.

Foi possível identificar redução significativa no valor do qual a Companhia Omega teve que proceder e realizou a adição para fins de Imposto de Renda e da Contribuição Social. Os valores de risco totais comparativos entre os métodos PVA e CAP estão expressos na tabela a seguir:

Tabela 7: Comparação dos Métodos PVA x CAP

\begin{tabular}{c|r|r|r}
\cline { 2 - 4 } & \multicolumn{1}{c}{ Método PVA } & Método CAP & \multicolumn{1}{c}{ Diferença } \\
\hline Total Base & $\mathrm{R} \$ 31.083 .422,14$ & $\mathrm{R} \$ 74.991,04$ & $\mathrm{R} \$ 31.008 .431,10$ \\
\hline IRPJ & $\mathrm{R} \$ 7.770 .855,53$ & $\mathrm{R} \$ 18.747,76$ & $\mathrm{R} \$ 7.752 .107,77$ \\
\hline CSLL & $\mathrm{R} \$ 2.797 .507,99$ & $\mathrm{R} \$ 6.749,19$ & $\mathrm{R} \$ 2.790 .758,80$ \\
\hline Risco Imposto & $\mathrm{R} \$ 10.568 .363,53$ & $\mathrm{R} \$ 25.496,95$ & $\mathrm{R} \$ 10.542 .866,57$ \\
\hline Multa & $\mathrm{R} \$ 7.926 .272,64$ & - & $\mathrm{R} \$ 7.926 .272,64$ \\
\hline Juros & $\mathrm{R} \$ 228.276,65$ & - & $\mathrm{R} \$ 228.276,65$ \\
\hline Risco Total & $\mathrm{R} \$ 18.722 .912,82$ & $\mathrm{R} \$ 25.496,95$ & $\mathrm{R} \$ 18.697 .415,87$ \\
\hline
\end{tabular}

Fonte: elaborada pelos autores

Com base na representativa redução da contingência, a companhia Omega realizou a adição na apuração do Imposto de Renda e da Contribuição Social, considerando os montantes identificados pela utilização do método CAP. Da mesma forma, evidenciou a ReFAE - Revista da Faculdade de Administração e Economia, v. 9, n. 1, p. 168-190, 2018 
necessidade de implementação do cálculo do preço de transferência como uma rotina mensal, para que esse seja utilizado no futuro como uma ferramenta de gestão, auxiliando o processo de tomada de decisão, principio esse inerente a contabilidade.

\section{Considerações finais}

Realizadas as análises sobre os dados e relatórios obtidos referente ao ano-calendário de 2015, foi possível apurar uma contingência passiva considerável, na maneira como a Companhia Omega estava efetuando o cálculo de preço de transferência.

Dessa forma, por meio do presente estudo, demonstraram-se as alterações no método escolhido de modo a minimizar os impactos econômicos que incidiriam pelo método PVA, o qual vinha sendo utilizado.

É importante destacar que a Sociedade não chegou a ter essa efetiva despesa em decorrência do equivoco cometido, tendo em vista que as declarações ainda não foram prestadas para as autoridades fiscais, bem como ainda não sofreu início de processo de fiscalização sobre esse assunto.

Contudo, considerando o cenário de fiscalização, e possível incidência de multa e juros sobre os valores envolvidos, obviamente ainda passíveis de discussão pela companhia Omega em esfera administrativa e judicial, pode-se inferir que com a revisão dos cálculos do preço de transferência, por meio desse trabalho, conseguiu-se sanar essa deficiência que pode ser quantificada em aproximadamente $\mathrm{R} \$ 18,7$ milhões.

Destarte, consegue-se defender a implementação do cálculo de preço de transferência como uma ferramenta de gestão, o qual deverá ser realizado através de uma rotina de análise mensal. Isto, pois, com a aplicação de todos os métodos factíveis, em relação às operações realizadas pela Companhia, permite-se que a instituição efetue as alterações necessárias nos preços que estão sendo praticados. Sobretudo tendo em vista que o objetivo principal é mitigar as penalizações impostas pelo inadimplemento à legislação vigente e que os cálculos têm por base a média anual dos preços realizados nas operações.

\section{Referências}

BEUREN, I. M. et al. Como Elaborar Trabalhos Monográficos em Contabilidade. 3. ed. São Paulo: Atlas, 2008

BRASIL. Lei do Ajuste Tributário n 9.430, de 27 de dezembro de 1996. http://www.receita.fazenda.gov.br/Legislacao/leis/Ant2001/lei943096.htm. Acesso em: 10/05/2016. 
BRASIL. Lei ${ }^{\circ}$ 6.404, de 15 de dezembro de 1976.

http://www.planalto.gov.br/ccivil_03/leis/16404consol.htm. Acesso em: 14/05/2016.

BRASIL. Lei $\mathrm{n}^{\circ} 7.689$

http://www.planalto.gov.br/ccivil_03/leis/L7689.htm. Acesso em: 12/05/2016.

BRASIL. Instrução Normativa RFB no 1.037, de 04 de junho de 2010

http://www.receita.fazenda.gov.br/Legislacao/ins/2010/in10372010.htm. Acesso em: $12 / 05 / 2016$.

BRASIL. Decreto - Lei 1.598 de 26 de dezembro de 1977. Brasília, DF, 26 dez. 1977. http://www.planalto.gov.br/ccivil_03/decreto-lei/del1598.htm. Acesso em: 05/05/2016.

BRASIL. Decreto - 3.000

http://www.planalto.gov.br/ccivil_03/decreto/d3000.htm. Acesso em: 02/05/2016.

BRASIL. CÓDIGO TRIBUTÁRIO BRASILEIRO

http://www.planalto.gov.br/ccivil_03/leis/L5172Compilado.htm. Acesso em: 02/04/2016.

BRASIL. Instrução Normativa RFB n 1.312, de 28 de dezembro de 2012.

http://www.receita.fazenda.gov.br/Legislacao/ins/2012/in13122012.htm. Acesso em: 10/03/2016.

BRASIL. Lei 9.718 de 27 de novembro de 1998. Brasília, DF, 27 nov. 1998.

http://www.receita.fazenda.gov.br/Legislacao/leis/Ant2001/lei971898.htm. Acesso em: $10 / 05 / 2016$.

BRASIL. Perguntas e Respostas da Receita Federal do Brasil.

http://www.receita.fazenda.gov.br/pessoajuridica/dipj/2000/orientacoes/lucroreal.htm. Acesso em: 02/05/2016.

BRASIL. Carga Tributária no Brasil 2014

http://idg.receita.fazenda.gov.br/dados/receitadata/estudos-e-tributarios-e-aduaneiros/estudose-estatisticas/carga-tributaria-no-brasil/29-10-2015-carga-tributaria-2014. Acesso em:

$10 / 03 / 2016$.

BRASIL. Manual de Orientação do Leiaute da Escrituração Contábil Fiscal (ECF) http://sped.rfb.gov.br/estatico/D5/2BF489D2C4AAFB80402C9D5892E7D0F7CACE47/Man ual_de_Orienta\%C3\%A7\%C3\%A3o_da_ECF_2016_05_25.pdf. Acesso em: 10/05/2016.

CECCONELlO, A. R.; BARBOSA, C. F.; CÉLICE, E. S.; KOUNROUZAN M. C; GIORGI, W. A. B. Métodos e Técnicas de Pesquisa em Contabilidade. São Paulo: Saraiva, 2003.

CERVO, A. L. ; BEVIAN, P. A. e SILVA, R. Metodologia Científica. São Paulo. Pearson Prentice Hall, 2006.

DUARTE, S. I. Preços de Transferência. 1. ed. São Paulo: Saint Paul, 2005.

FABRETTI, L. C. Contabilidade Tributária. 11. ed. São Paulo: Atlas, 2009.

ReFAE - Revista da Faculdade de Administração e Economia, v. 9, n. 1, p. 168-190, 2018 
GIL, A. C. Métodos e Técnicas de Pesquisa Social. 6. ed. São Paulo: Atlas, 2008.

GREGORIO, R. M. Preços de Transferência. São Paulo: Quartier Latin, 2011.

HIGUCHI, H. Imposto de Renda das Empresas: interpretação e prática. 30. ed. São Paulo: IR Publicações, 2005.

IUDÍCIBUS, S.; MARTINS, E.; KANITZ, S.; et al Contabilidade Introdutória. São Paulo: Atlas, 2010.

MACHADO, H. B. Curso de Direito Tributário. 31. ed. São Paulo: Malheiros, 2010.

LAKATOS, E. M. ; MARCONI, Marina de Andrade. Fundamentos de Metodologia Científica. 5. ed. São Paulo: Atlas, 2003.

NEPOMUCENO, F. Preço de Transferência. São Paulo: IOB - Thompson, 2003

OLIVEIRA, G. P. Contabilidade Tributária: revisada e atualizada conforme lei $\mathbf{n}^{\circ}$ 11.638/2007 e medida provisória n 449/2008. 3. ed. São Paulo: Saraiva, 2009.

SILVA, A. C. Metodologia da Pesquisa Aplicada à Contabilidade: Orientações de Estudos, Projetos, Artigos, Relatórios, Monografias, Dissertações, Teses. 3. ed. São Paulo: Atlas, 2010.

VIEIRA, A. Teoria e Prática Cambial: exportação e importação. 4. ed. São Paulo: Aduaneiras, 2010. 